\title{
Modulation of Myotilin and Fylamin C in Various Muscle Diseases: A Microarray Analysis
}

\author{
Cristina Sanfilippo ${ }^{1,+}$ and Michelino Di Rosa ${ }^{2,3, t, *}$ \\ 1 Department of Medical Sciences, Surgicals and Advanced Technologies G.F. Ingrassia, \\ Section of Neuroscience, University of Catania, Via Santa Sofia 78, 95123 Catania, Italy; \\ cri.sanfilippo@gmail.com \\ 2 Department of Biomedical and Biotechnology Sciences, University of Catania, Via Androne 83, \\ 95123 Catania, Italy \\ 3 Italian Center Studies of Osteopathy, 95123 Catania, Italy \\ * Correspondence: mdirosa@unict.it; Tel.: +39-095-313-429 \\ + These authors contributed equally to this work. \\ Academic Editor: Giuseppe Musumeci \\ Received: 18 January 2016; Accepted: 4 February 2016; Published: 19 February 2016
}

\begin{abstract}
The cytoskeletal protein plays a significant role in the stability of thin filaments during muscle contraction. Mutations in these genes have been associated with various muscles diseases. Myotilin (MYOT) and Fylamin C (FLNC) belong to the cytoskeleton protein family and are associated with different myopathies. We analyzed two microarray datasets obtained from the NCBI Gene Expression Omnibus databank (accession number GDS2855 and GDS1956) in order to verify the modulation of MYOT and FLNC in eight human skeletal muscle diseases. For these studies we also used: the open source tools the Human Protein Atlas to confirm by Immunohistochemistry (IH) the MYOT and FLNC tissue expression; Genome-scale Integrated Analysis of gene Networks in Tissues (GIANT) to identify the genes network; COMPARTMENT to identify the localization in cells. We showed that both MYOT and FLNC were significantly modulated in various muscle diseases. In particular, MYOT and FLNC mRNA were significantly downregulated in Acute quadriplegic myopathy (AQM) and Amyotrophic Lateral Sclerosis (ALS) compared to normal human skeletal muscle. Furthermore, the GIANT analysis showed a relationship confidence of 0.23 to MYOT and FLNC, confirming their strong correlation. These data provide to support our hypothesis that a positive correlation exists between MYOT and FLNC. Larger studies are needed to evaluate if MYOT and FLNC may be a promising clinical biomarker in subjects with diseases of the muscle.
\end{abstract}

Keywords: MYOT; FLNC; ASL; muscle diseases

\section{Introduction}

Skeletal muscle is an organ system specialized in locomotion and energy metabolism in multicellular organisms. Degeneration of muscle cell integrity caused by genetic mutations or degenerative diseases leads to progressive muscle wasting with harmful consequences, including dysfunction and early death. Mutations in a wide range of proteins, including many structural proteins and enzymes that post-translationally modify some of these proteins, have been implicated in muscular dystrophy [1].

The muscles and neurons supplying muscle operate as a functional unit, and disease of both systems results in muscular atrophy (wasting) and paralysis. Regarding neuronal degeneration, we can observe two different clinical presentations. Muscle weakness typical of upper motor neuron 
disease is seen in stroke, multiple sclerosis [2], tumors [3], and spinal cord injury [4], where the muscle bulk is usually well preserved.

Degeneration of the lower neuron, instead, produces a flaccid muscle weakness. The main effect is muscle atrophy caused by the damage and eventual death of neurons that lead to denervation of the muscle. The most common disease that involves upper and lower motor neurons is Amyotrophic Lateral Sclerosis (ALS) — a fatal adult-onset neurodegenerative disease characterized by the selective degeneration of both upper and lower motor neurons. Dysfunction and, ultimately, death of motor neurons results in the progressive paralysis of skeletal muscles and respiratory failure within 2-5 years of disease onset [5].

Concerning muscle disease, muscular dystrophies are a vast group of hereditary disorders characterized by progressive muscular atrophy and weakness [6]. Among the several varieties of muscular dystrophy, we considered the most important. Duchenne muscular dystrophy (DMD) is an X-linked condition; that is, a defect of a gene on the $\mathrm{X}$ chromosome is responsible for the disease. Muscle degeneration is due to the lack of a protein called dystrophin, which causes a disruption of the membrane covering the muscle fiber; the results are the entry of excess amounts of calcium ions into the cell and cell degeneration [7].

Becker muscular dystrophy (BMD) is similar to the DMD except that it appears later in life and progresses more slowly. It is due to different damage to the same gene on the $\mathrm{X}$ chromosome that causes DMD. It leads to a reduction of the amount of dystrophin produced [8].

Facioscapulohumeral muscular dystrophy (FSHD) is considered an autosomal dominant disorder, with a typical onset within the second decade of life $[9,10]$.

The classical FSHD phenotype is characterized by progressive facial, shoulder girdle, and pectoral muscle weakness and atrophy. Disease progression may lead to the involvement of abdominal and pelvic muscles, causing lumbar hyperlordosis and a waddling gait. Weakness of anterior leg muscles results in a steppage gait [11]. Emery-Dreifuss muscular dystrophy (EDMD) is a condition that chiefly affects muscles used for movement (skeletal muscles) and heart (cardiac) muscle. Most affected individuals also experience slowly progressive muscle weakness and wasting, beginning in the muscles of the upper arms and lower legs, and progressing to muscles in the shoulders and hips. The types of EDMD are distinguished by their pattern of inheritance: $X$-linked, autosomal dominant, and autosomal recessive. Although the three types have similar signs and symptoms, researchers believe that the features of autosomal dominant EDMD are more variable than the other types [12].

The idiopathic inflammatory myopathies (IIM), including dermatomyositis (DM), polymyositis (PM), inclusion body myositis (IBM), and immune-mediated necrotizing myopathy (NM), are heterogeneous conditions. Their precise etiology is unknown and they are characterized by muscle weakness and inflammation, combined with elevated muscle enzymes and characteristic changes on electromyography and muscle biopsy [13-15].

The disease frequently occurs in association with other autoimmune diseases, such as rheumatoid arthritis and progressive systemic sclerosis, and it can be associated with cancer in a significant proportion of older patients, particularly those with juvenile dermatomyositis (JDM) [16].

The cytoskeleton protein plays an important role in diseases of the muscle. Myotilin (MYOT), palladin, and myopalladin form a small homologous group of cytoskeletal proteins functioning as scaffolds that regulate actin organization [17]. MYOT, the founding member of the group, is a $57 \mathrm{kDa}$ actin-binding protein found at sarcomeric Z-discs of both skeletal and cardiac muscle [18]. It plays a role as structural organizer of the cytoskeleton and it participates in the assembly and structural maintenance of the sarcomeric Z-discs. Point mutations in MYOT cause muscle disorders such as limb-girdle muscular dystrophy type 1A (LGMD1A) and myofibrillar myopathy. The MYOT sequence is 498 residues in length and it contains two consecutive Ig-domains close to its C-terminus, followed by a short C-terminal tail [18]. The unique N-terminal part of MYOT has areas rich in serine residues and it carries potential phosphorylation sites. MYOT has been shown to interact with actin, $\alpha$-actinin, Fylamin C (FLNC) [19], and FATZ-1/FATZ-2 (FATZ: filamin-, actinin-, and telethonin-binding protein 
of the Z-disc) [20], and recently also with Enigma family proteins [21]. The actin-binding propensity of MYOT has been mapped to the Ig-domains. The Ig-domains are also responsible for the formation of MYOT homodimers and for the interaction with FLNC. The $\alpha$-actin in binding site resides at the $\mathrm{N}$-terminal section of MYOT. The disease-causing mutations of MYOT are located to the N-terminal part of the protein, and they do not seem to affect the MYOT-actin interaction.

FLNC is a muscle-specific member of the filamin family of proteins [22-24]. Filamins have an actin-binding domain at their $\mathrm{N}$-terminus, and a C-terminal Ig-like domain that enables the protein to dimerise. In addition to its role in organising actin filaments, FLNC interacts with several other proteins, including $\mathrm{g}$ and $\mathrm{d}$ sarcoglycans, MYOT, calsarcin, and b1 integrin. These interactions suggest that FLNC plays an important role during myofibrillo genesis [25-27]. The FLNC gene (FLNC) encompasses 46 exons and codes for 2705 amino acids [19,28]. FLNC-deficient mice have defects in primary myogenesis, resulting in reduced myotubes and reduced muscle fibres; as a result, animals die shortly after birth [29].

\section{Materials and Methods}

\subsection{Bioinformatics Analysis}

For this study, we analyzed two microarray datasets obtained from the NCBI (Available online: http:/ / www.ncbi.nlm.nih.gov/) under accession number GDS2855 and GDS1956 in order to define a correlation between the MYOT and FLNC, gamma (FLNC) gene in biopsies of eight muscle specimens from patients with various muscle diseases compared to 18 healthy human skeletal muscle donor. In cases where multiple probes insisted on the same NCBI GeneID, we used those with the highest variance. Groups studied were: Normal human skeletal muscle, Acute quadriplegic myopathy (AQM; critical care myopathy), Juvenile dermatomyositis (JDM), Amyotophic lateral sclerosis (ALS), spastic paraplegia (SPG4; spastin), Fascioscapulohumeral muscular dystrophy (FSHD), Emery-Dreifuss muscular dystrophy (both X-linked recessive emerin form and autosomal dominant Lamin A/C form), Becker muscular dystrophy (BMD; partial loss of dystrophin), Duchenne muscular dystrophy (DMD; complete loss of dystrophin). For the microarrays, the RNA extracted from muscle biopsy was flash-frozen in isopentane cooled in liquid nitrogen immediately after excision. Complete experimental details can be retrieved in the publication by Bakay et al. and Dadgar et al. [30,31].

\subsection{GIANT: Genome-Scale Integrated Analysis of Gene Networks in Tissues}

The MYOT and FLNC gene pathway is obtained from the GIANT database (Available online: http:/ / giant.princeton.edu/), setting the tissue menu to muscle, the Network filter with Minimum relationship confidence 0.13 , and Maximum number of genes to 20 . No enriched biological processes were found.

The GIANT software predicted a functional interaction networks of 144 human tissues and cell types using data from Bayesian methodology that incorporated diverse experiments, ranging over tissue and disease states. GIANT was created by the Laboratory for Bioinformatics and Functional Genomics in the Lewis-Sigler Institute for Integrative Genomics at Princeton University. GIANT tissue networks integrate 987 genome-scale datasets, encompassing $\sim 38,000$ conditions from $\sim 14,000$ publications and includes both expression and interaction measurements. The obtained networks show tissue-specific functional interactions. The GIANT software determines associations from a genome-wide association study (GWAS) and potentially identifies additional disease-associated genes. This type of approach (NetWAS) can be applied to any GWAS study, and does not require that the phenotype or disease have any known associated genes [32].

\subsection{Immunohistochemestry (IH) by "the Human Protein Atlas"}

We also decided to verify MYOT (HPA037733) and FLNC (HPA006135) protein expression by Immunohistochemestry (IH) using the Human Protein Atlas (Available online: http://www. 
proteinatlas.org/) [33-35]. The result of the immunostaining of each antibody is compared with available gene/RNA/protein characterization data, resulting in two different validations: Literature conformity and RNA consistency. Literature conformity is based on conformance of the expression pattern to available gene/protein characterization data in scientific literature and data from bioinformatics predictions. UniProt is used as the main source of gene/protein characterization data, and, when relevant, available publications and other sources of information are probed in-depth. Extensive or sufficient gene/protein data requires that there is evidence of the existence at the protein level and that a substantial quantity of published experimental data is available from literature and public databases. Limited protein/gene data does not require evidence of existence at the protein level and refers to genes for which only bioinformatics predictions and scarce published experimental data is available. RNA consistency is based on a comparison of immunohistochemistry data with the internally-generated RNA-Seq data.

The different options of literature conformity are:

- Consistent with extensive gene/protein characterization data

- Consistent with gene/protein characterization data

- Partly consistent with extensive gene/protein characterization data

- Partly consistent with gene/protein characterization data

- No available gene/protein characterization data

- Not consistent with gene/protein characterization data

- Not done

The immunohistochemical protocols used result in a brown-black staining, localized where an antibody has bound to its corresponding antigen. The section is furthermore histochemically counterstained with hematoxylin to enable visualization of microscopic features. Hematoxylin staining is unspecific, and results in a blue coloring of both cells and extracellular material.

\subsection{Analysis of Cellular Localization by "COMPARTMENTS"}

COMPARTMENTS is a web resource that integrates evidence on protein subcellular localization from manually curated literature, high-throughput screens, automatic text mining, and sequence-based prediction methods. All evidence is mapped to common protein identifiers and Gene Ontology terms, and are further unified by assigning confidence scores that facilitate comparison of the different types and sources of evidence and visualize these scores on a schematic cell [36].

\subsection{Statistical Analysis}

For statistical analysis, Prism 7 software (GraphPad Software, La Jolla, CA, USA) and SPSS 20.0 for IBM was used. Parametric tests were used. One-way ANOVA and $t$-tests with LSD (Fishers Least Significant Difference) correction were used to analyze the data, and significance was determined at $p<0.05$. Correlations were determined using Pearson's correlation.

\section{Results}

\subsection{MYOT and FLNC Tissue and Cellular Localization}

The analysis of the Human Protein Atlas showed high expression of MYOT and FLNC in the myocytes of skeletal muscle (Figure 1). The IH analysis showed a strong intensity and a quantity $>75 \%$ in the cytoplasmic membranes of myocytes. To confirm the localization of MYOT and FLNC, we performed analysis by COMPARTMENT, a piece of free online software. The software analysis showed that MYOT is prevalently expressed in the cytoskeleton and plasma membrane (confidence value 6). Regarding FLNC, the analysis showed that it is prevalently expressed in the cytosol (confidence value 5), the cytoskeleton (confidence value 3 ), the plasma membrane (confidence value 5), and the 
extracellular space (confidence value 3). These data confirm the specific localization of the two proteins in the skeletal muscle.

A)

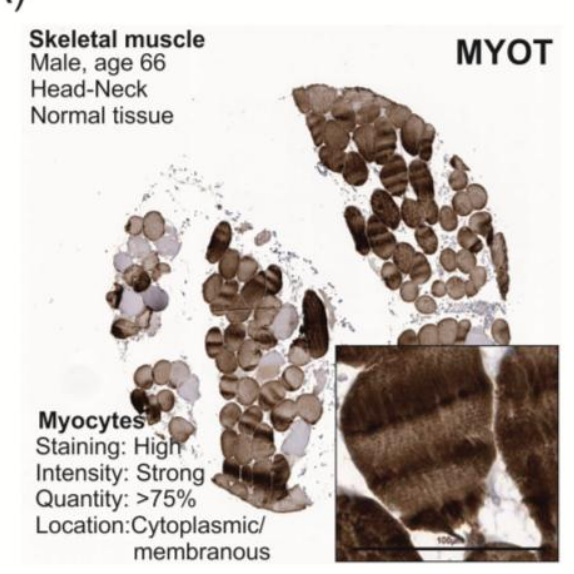

C)

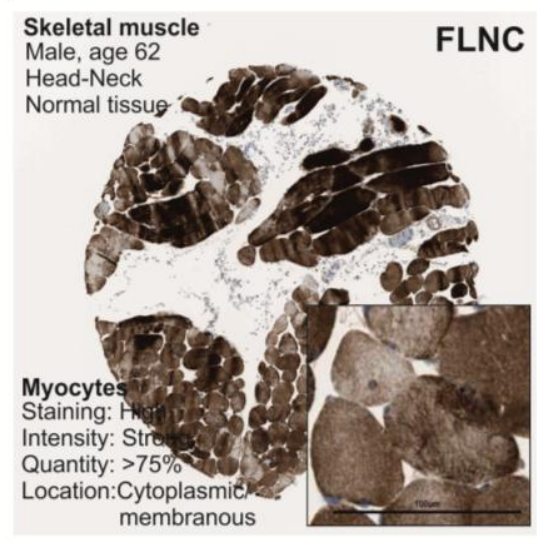

B)

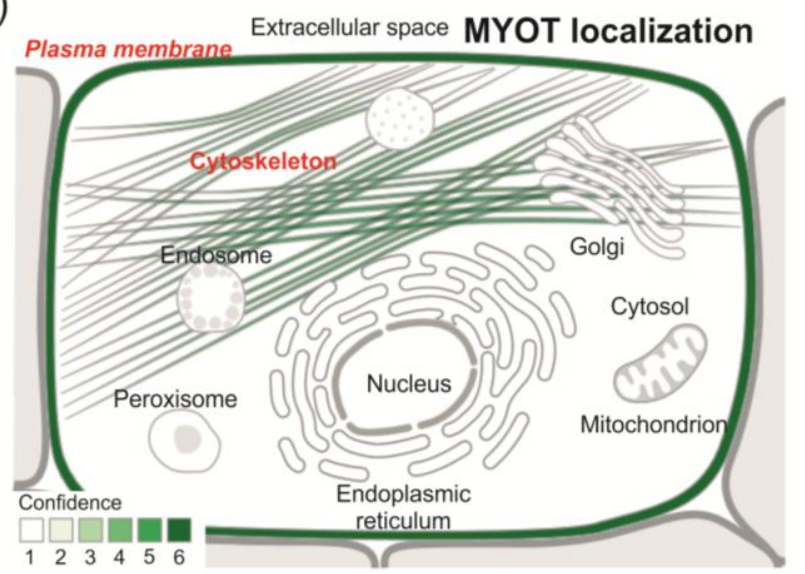

D)

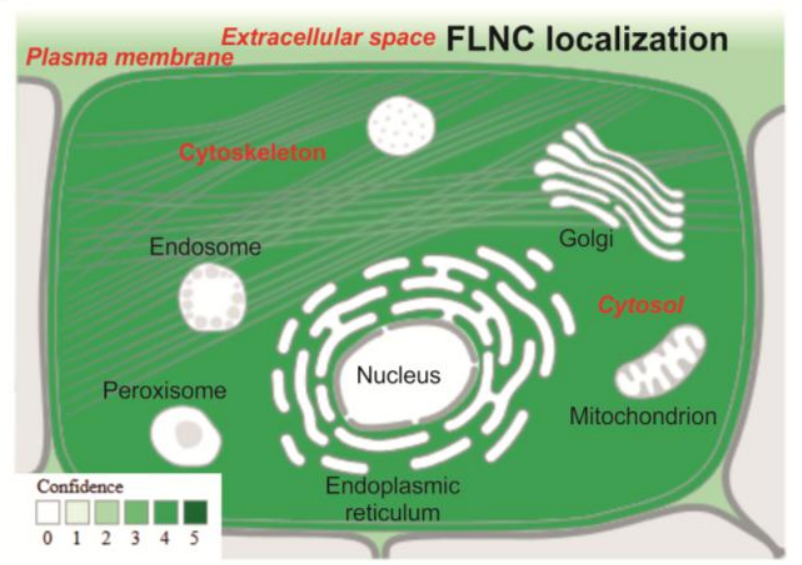

Figure 1. Tissue and subcellular localization of myotilin (MYOT) and fylamin C (FLNC). (A,C) Immunohistochemical (IH) analysis of MYOT and FLNC in skeletal muscle. The data were obtained from the Human Protein Atlas. A single representative section of skeletal muscle is shown. Expression of MYOT and FLNC in Skeletal muscle samples was evaluated as strong, moderate, weak and negative immunostaining. The expression of MYOT and FLNC was in myocytes. The localization was cytoplasmic membranous. Scale bars equal $100 \mu \mathrm{m}$; (B,D) Localization analysis by COMPARTMENTS. The software analysis showed that MYOT was prevalently expressed in the cytoskeleton and plasma membrane (confidence value 6). With regards to FLNC, the analysis showed that it is prevalently expressed in the cytosol (confidence value 5), cytoskeleton (confidence value 3), plasma membrane (confidence value 5), and extracellular space (confidence value 3 ).

\subsection{MYOT and FLNC Network}

In order to verify the close relationship between MYOT and FLNC, we performed a genes networks analysis using the GIANT software. The analysis automatically up-weights datasets relevant to a tissue from a large data compendium of different tissues and cell-types and returns a genes network map weighted through a relationship confidence score (Figure 2A). The analysis showed that MYOT and FLNC are related to 16 genes and the strongest relationship confidence score was between MYOT and FLNC (0.283) (Figure 2B). These results showed the close correlation of the two genes. 
A)

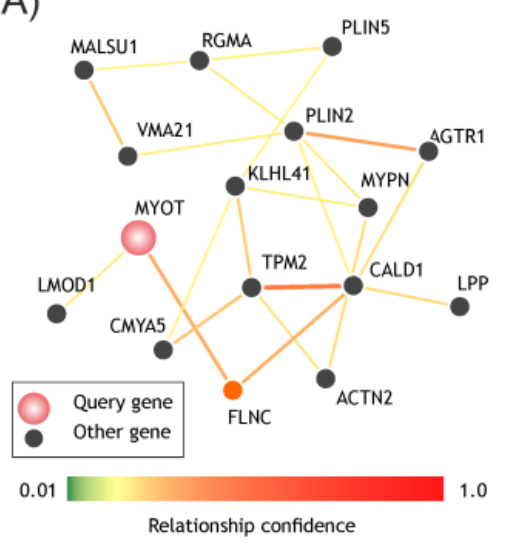

B)

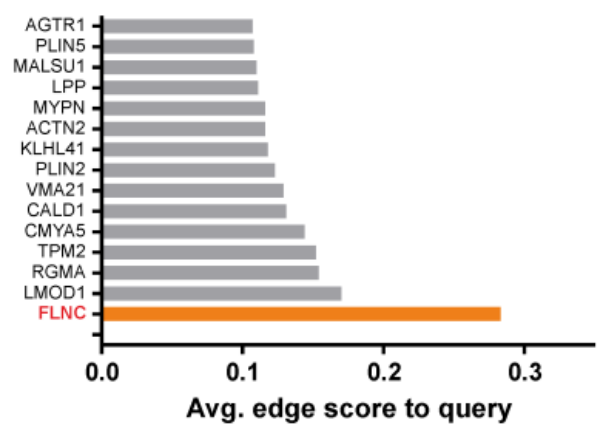

Figure 2. MYOT and FLNC network. (A) Genes networks analysis by GIANT software. The analysis showed 16 genes correlated to MYOT and FLNC; (B) The average score (relationship confidence) for MYOT and FLNC is 0.283 .

\subsection{MYOT and FLNC Expression Levels in Various Muscle Diseases}

In light of these results, we decided to analyze two microarray datasets obtained from the NCBI in order to define a correlation between the MYOT and FLNC genes in biopsies of eight muscle specimens from patients with various muscle diseases compared to a healthy human skeletal muscle donor (Figure 3). The results showed that MYOT was significantly downregulated in AQM $(p=0.00006)$, $\operatorname{YDM}\left(p=1.53 \times 10^{-9}\right), \operatorname{ALS}\left(p=1.72 \times 10^{-10}\right), \operatorname{EDMD}(p=0.005)$, and in $\operatorname{DMD}(p=0.020)$, compared to a healthy human skeletal muscle donor. Regarding the FLNC expression, we showed that it was significantly downregulated in AQM $(p=0.00041)$, ALS $(p=0.022)$, SPG4 $(p=0.0025)$, and BMD $(p=0.0026)$, compared to a healthy human skeletal muscle donor. These results showed a similar expression trend of MYOT and FLNC in AQM and ALS.

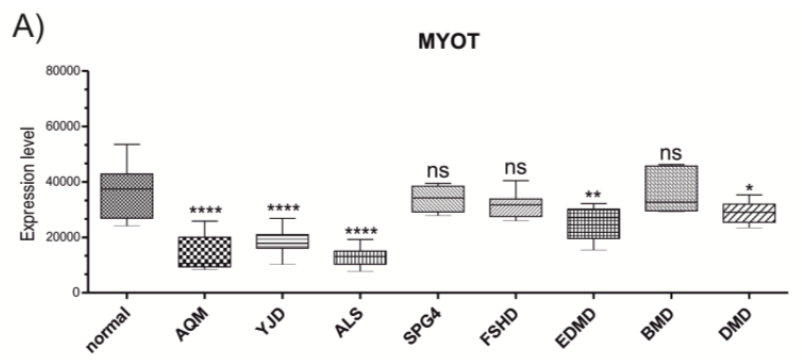

B)

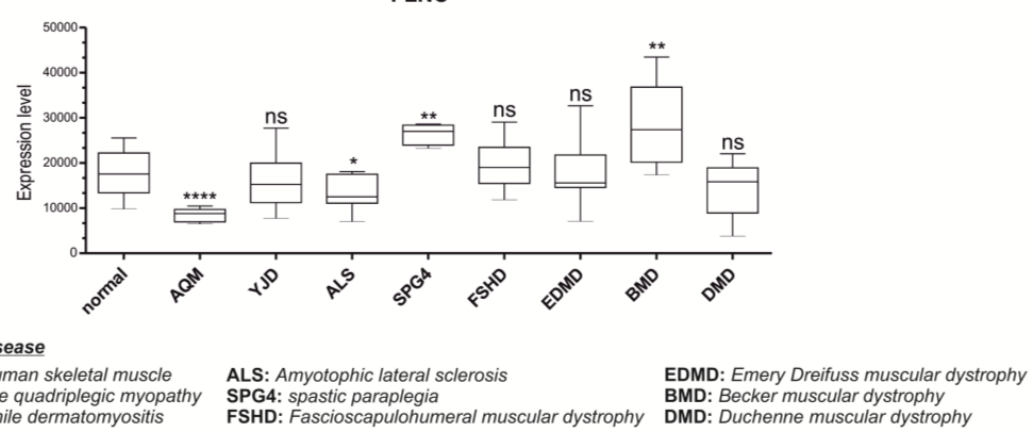

Figure 3. Expression levels of MYOT and FLNC mRNA in various muscle diseases. Datasets accession number GDS2855 and GDS1956. Data are expressed as intensity expression levels and presented as box and whiskers. $p$ Values $<0.01$ were considered to be statistically significant ${ }^{*} p<0.01$; ${ }^{* *} p<0.001$; **** $p<0.00001)$. ns: not statistically significant. 


\subsection{MYOT and FLNC Correlation}

To verify the correlation between MYOT and FLNC inside muscle degeneration, we decided to perform a Pearson's correlation analysis. We found a positive correlation between MYOT and FLNC mRNA levels $(r=0.46 ; p<0.0001)$ across all diseases. Only ALS shows a strong positive correlation between MYOT and FLNC $r=0.817, p<0.007$ (Figure 4).

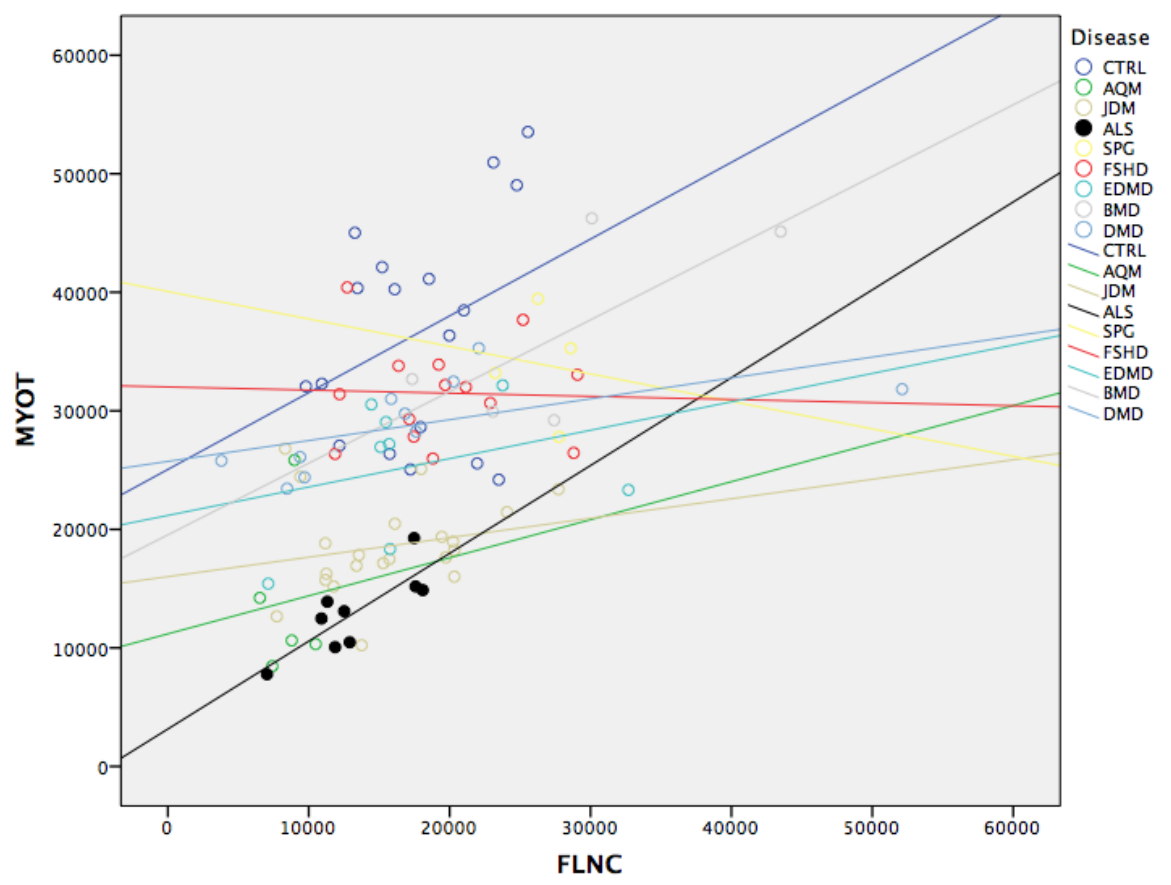

Figure 4. MYOT levels in relation to FLNC levels with respect to different diseases. The full black symbols represent the positive correlation between FLNC and MYOT. The regression lines in the figures are only for visualization.

\section{Discussion}

In this article, we demonstrated for the first time that MYOT and FLNC are closely related in ALS and significantly downregulated in different diseases of the muscle. Furthermore, our results show that these molecules are highly expressed in different compartments of myocytes.

It is showed that a MYOT mutation can also cause a limb girdle-like phenotype that has been designated as LGMD1A [37] and as a distal myopathy [38,39]. The Individuals with LGMD show weakness and wasting restricted to the limb musculature. LGMD patients show relative sparing of the bulbar muscles depending on the genetic subtype [40]. Though ALS and LGMD are two diseases which differ in many characteristics (ALS affects the motor neurons while muscular dystrophy-like LGMD affects the muscles of the body) the downstream effect is the muscle and the protein that govern its action. The alteration in MYOT expression in ALS seems to be an effect, not a cause. Muscular atrophy determines myofibril breakdown involving the ubiquitin ligases MuRF1 and Trim32. MuRF1 is essential for the ubiquitin-dependent degradation of proteins comprising the thick filament, while Trim32 catalyzes the disassembly and degradation of the desmin cytoskeleton, Z-band, and thin filament proteins, which are linked processes. [41]. It has been shown that MYOT interacts with regulators of signaling cascades and MuRF1 ubiquitin ligases [42]. MYOT cross-links actin filaments into large stable bundles, both in vitro and in cells [43]. Furthermore, our results showed that MYOT was significantly downregulated both in skeletal muscle of ALS patients and in AQM, YJD, EDMD, and DMD. In all these pathologies, the role played by MYOT is common. The alteration of this molecule probably reduces the efficient mechanism of muscle contraction (Figure 5). 


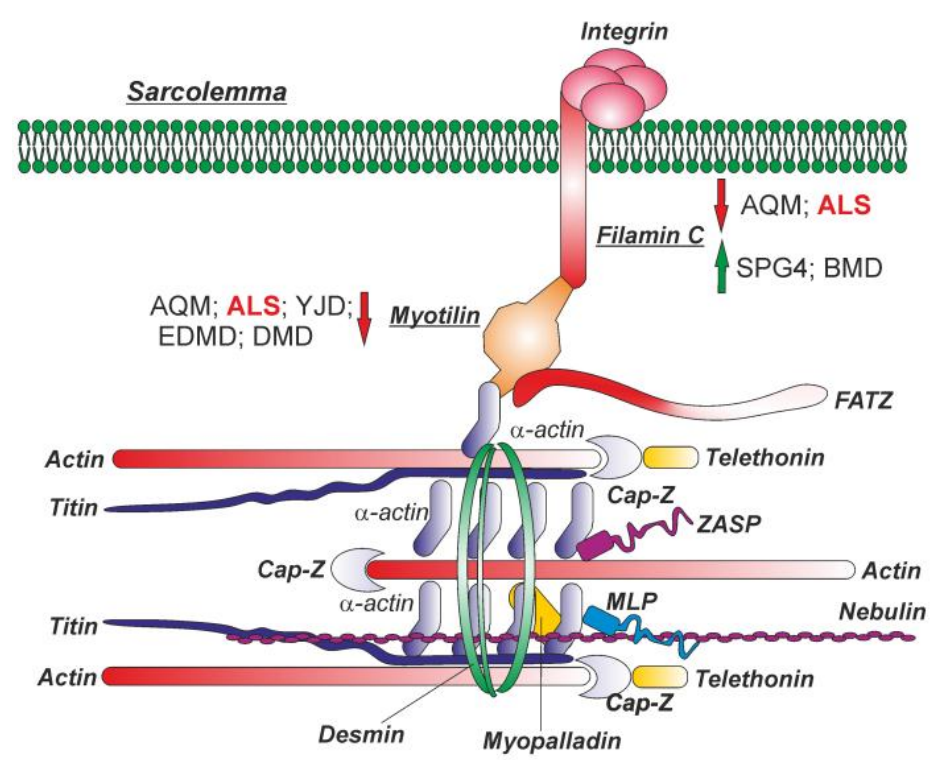

Figure 5. Schematic representation of components of the Z-disc. The Z-disc forms the borders of individual sarcomeres. The Z-discs largely consists of $\alpha$-actin homodimers organised in an antiparallel fashion and providing a backbone for the insertions of actin filaments, as well as titin and nebulin. Desmin filaments surround the Z-disc; they interconnect the filaments to each other, and link the myofibrils to the sarcolemma and nuclear membrane. Myotilin interacts with several Z-disc proteins, including $\alpha$-actin, filamin C, F-actin, and FATZ. Filamin C binds to actin filaments, and interacts with several proteins, including myotilin, FATZ, and b1 integrin. ZASP binds directly to $\alpha$-actin. ZASP: Z-band alternatively spliced PDZ-motif-containing protein; FATZ: filamin-, actin-, and telethonin-binding protein of the Z-disc; MLP: muscle LIM protein.

Regarding FLNC, we show that in AQM, ALS, SPG4, and BMD, the expression levels are downregulated in muscle biopsy compared to healthy donor. There are several pieces of evidence demonstrating that FLNC plays a critical role in the degeneration of skeletal muscles. Interestingly, FLNC interacts with both DGC (dystrophin-associated glycoprotein complex) [25] and integrin [20,44], as well as with the Z-disk proteins MYOT [19], FATZ-1 [45], and myopodin [46] through its C-terminal region. Such localization and protein interaction suggests that FLNC functions in maintaining the mechanical integrity of muscle cells. Recently, mutations in the FLNC gene were identified in patients having myofibrillar myopathy [47-50].It has been shown that mutations in the Tar DNA binding protein of $43 \mathrm{kDa}$ (TDP-43; TARDBP) are associated with ALS and Frontotemporal Lobar Degeneration with TDP- $43^{+}$inclusions (FTLD-TDP) [51]. In double mutants, the muscle-specific actin binding protein FLNC is up-regulated. Strikingly, FLNC is increased in FTLD-TDP patients [52]. This expression in smooth muscle cells and the TDP-43 loss of function could be considered as a disease mechanism [52]. These data confirm the critical role played by FLNC and the actin-binding protein in the degeneration of skeletal muscles. The physical interaction occurring between MYOT and FLNC has been widely studied. The N-terminal half of MYOT contains a binding site for $\alpha$-actin [18], and its C-terminus, which exhibits two Ig-like domains, mediates binding to FLNC [19]. The modulation of MYOT seems closely associated to FLNC. This could partly explain the correlation found in ALS patients.

This evidences supports our hypothesis that MYOT and FLNC play a central role in diseases of the muscle. Additional studies are needed to clarify the biological function elicited by these two molecules in the various diseases of muscle degeneration.

Author Contributions: Cristina Sanfilippo and Michelino Di Rosa conceived and designed the experiments; Cristina Sanfilippo and Michelino Di Rosa performed the experiments; Cristina Sanfilippo and Michelino Di Rosa analyzed the data; Cristina Sanfilippo and Michelino Di Rosa contributed reagents/materials/analysis tools; Cristina Sanfilippo and Michelino Di Rosa wrote the paper. 
Conflicts of Interest: The authors declare no conflict of interest. The founding sponsors had no role in the design of the study; in the collection, analyses, or interpretation of data; in the writing of the manuscript, and in the decision to publish the results.

\section{Abbreviations}

The following abbreviations are used in this manuscript:

$\begin{array}{ll}\text { MYOT } & \text { myotilin } \\ \text { FLNC } & \text { filamin C, gamma } \\ \text { AQM } & \text { Acute Quadriplegic Myopathy } \\ \text { JDM } & \text { Juvenile Dermatomyositis } \\ \text { ALS } & \text { Amyotrophic Lateral Sclerosis } \\ \text { SPG4 } & \text { Spastic Paraplegia } \\ \text { FSHD } & \text { Fascioscapulohumeral Muscular Dystrophy } \\ \text { EDMD } & \text { Emery Dreifuss Muscular Dystrophy } \\ \text { BMD } & \text { Becker Muscular Dystrophy } \\ \text { DMD } & \text { Duchenne Muscular Dystrophy } \\ \text { GIANT } & \text { Genome-scale Integrated Analysis of gene Networks in Tissues } \\ \text { IH } & \text { Immunohistochemestry } \\ \text { FATZ } & \text { filamin-, actinin-, and telethonin-binding protein of the Z-disc } \\ \text { MLP } & \text { muscle LIM protein } \\ \text { ZASP } & \text { Z-band alternatively spliced PDZ-motif-containing protein }\end{array}$

\section{References}

1. Grewal, P.K.; Hewitt, J.E. Glycosylation defects: A new mechanism for muscular dystrophy? Hum. Mol. Genet. 2003, 12, R259-R264. [CrossRef] [PubMed]

2. Schmitt, F.; Hussain, G.; Dupuis, L.; Loeffler, J.P.; Henriques, A. A plural role for lipids in motor neuron diseases: Energy, signaling and structure. Front. Cell. Neurosci. 2014, 8. [CrossRef] [PubMed]

3. Antoine, J.C.; Camdessanche, J.P. Paraneoplastic disorders of the peripheral nervous system. Presse Med. 2013, 42, e235-e244. [CrossRef] [PubMed]

4. Doherty, J.G.; Burns, A.S.; O'Ferrall, D.M.; Ditunno, J.F., Jr. Prevalence of upper motor neuron vs. lower motor neuron lesions in complete lower thoracic and lumbar spinal cord injuries. J. Spinal Cord Med. 2002, 25, 289-292. [PubMed]

5. Bruijn, L.I.; Miller, T.M.; Cleveland, D.W. Unraveling the mechanisms involved in motor neuron degeneration in ALS. Ann. Rev. Neurosci. 2004, 27, 723-749. [CrossRef] [PubMed]

6. Mercuri, E.; Muntoni, F. Muscular dystrophies. Lancet 2013, 381, 845-860. [CrossRef]

7. Fairclough, R.J.; Wood, M.J.; Davies, K.E. Therapy for duchenne muscular dystrophy: Renewed optimism from genetic approaches. Nat. Rev. Genet. 2013, 14, 373-378. [CrossRef] [PubMed]

8. Viswanathan, V. Current concepts in dystrophinopathies. Indian J. Pediatr. 2015, 82, 172-178. [CrossRef] [PubMed]

9. Lunt, P.W.; Compston, D.A.; Harper, P.S. Estimation of age dependent penetrance in facioscapulohumeral muscular dystrophy by minimising ascertainment bias. J. Med. Genet. 1989, 26, 755-760. [CrossRef] [PubMed]

10. Tawil, R.; van der Maarel, S.; Padberg, G.W.; van Engelen, B.G. 171st ENMC international workshop: standards of care and management of facioscapulohumeral muscular dystrophy. Neuromuscul. Disord. NMD 2010, 20, 471-475. [CrossRef] [PubMed]

11. McDonald, C.M. Clinical approach to the diagnostic evaluation of hereditary and acquired neuromuscular diseases. Phys. Med. Rehabil. Clin. N. Am. 2012, 23, 495-563. [CrossRef] [PubMed]

12. De Smet, L. Emery-dreifuss muscular dystrophy. Genet. Counsel. 2004, 15, 91-94. [PubMed]

13. Carstens, P.O.; Schmidt, J. Diagnosis, pathogenesis and treatment of myositis: Recent advances. Clin. Exp. Immunol. 2014, 175, 349-358. [CrossRef] [PubMed] 
14. Rider, L.G.; Miller, F.W. Deciphering the clinical presentations, pathogenesis, and treatment of the idiopathic inflammatory myopathies. JAMA 2011, 305, 183-190. [CrossRef] [PubMed]

15. Dalakas, M.C. Inflammatory muscle diseases. N. Engl. J. Med. 2015, 373, 393-394. [PubMed]

16. Mira-Avendano, I.C.; Parambil, J.G.; Yadav, R.; Arrossi, V.; Xu, M.; Chapman, J.T.; Culver, D.A. A retrospective review of clinical features and treatment outcomes in steroid-resistant interstitial lung disease from polymyositis/dermatomyositis. Respir. Med. 2013, 107, 890-896. [CrossRef] [PubMed]

17. Otey, C.A.; Rachlin, A.; Moza, M.; Arneman, D.; Carpen, O. The palladin/myotilin/myopalladin family of actin-associated scaffolds. Int. Rev. Cytol. 2005, 246, 31-58. [PubMed]

18. Salmikangas, P.; Mykkanen, O.M.; Gronholm, M.; Heiska, L.; Kere, J.; Carpen, O. Myotilin, a novel sarcomeric protein with two Ig-like domains, is encoded by a candidate gene for limb-girdle muscular dystrophy. Hum. Mol. Genet. 1999, 8, 1329-1336. [CrossRef] [PubMed]

19. Van der Ven, P.F.; Wiesner, S.; Salmikangas, P.; Auerbach, D.; Himmel, M.; Kempa, S.; Hayess, K.; Pacholsky, D.; Taivainen, A.; Schroder, R.; et al. Indications for a novel muscular dystrophy pathway. Gamma-filamin, the muscle-specific filamin isoform, interacts with myotilin. J. Cell Biol. 2000, 151, 235-248. [CrossRef] [PubMed]

20. Gontier, Y.; Taivainen, A.; Fontao, L.; Sonnenberg, A.; van der Flier, A.; Carpen, O.; Faulkner, G.; Borradori, L. The Z-disc proteins myotilin and FATZ-1 interact with each other and are connected to the sarcolemma via muscle-specific filamins. J. Cell Sci. 2005, 118, 3739-3749. [CrossRef] [PubMed]

21. von Nandelstadh, P.; Gronholm, M.; Moza, M.; Lamberg, A.; Savilahti, H.; Carpen, O. Actin-organising properties of the muscular dystrophy protein myotilin. Exp. Cell Res. 2005, 310, 131-139. [CrossRef] [PubMed]

22. Himmel, M.; van der Ven, P.F.; Stocklein, W.; Furst, D.O. The limits of promiscuity: Isoform-specific dimerization of filamins. Biochemistry 2003, 42, 430-439. [CrossRef] [PubMed]

23. van der Flier, A.; Sonnenberg, A. Structural and functional aspects of filamins. Biochim. Biophys. 2001, 1538, 99-117. [CrossRef]

24. Di Rosa, M.; Tibullo, D.; Saccone, S.; Distefano, G.; Basile, M.S.; Di Raimondo, F.; Malaguarnera, L. CHI3L1 nuclear localization in monocyte derived dendritic cells. Immunobiology 2016, 221, 347-356. [CrossRef] [PubMed]

25. Thompson, T.G.; Chan, Y.M.; Hack, A.A.; Brosius, M.; Rajala, M.; Lidov, H.G.; McNally, E.M.; Watkins, S.; Kunkel, L.M. Filamin 2 (FLN2): A muscle-specific sarcoglycan interacting protein. J. Cell Biol. 2000, 148, 115-126. [CrossRef] [PubMed]

26. Van der Ven, P.F.; Obermann, W.M.; Lemke, B.; Gautel, M.; Weber, K.; Furst, D.O. Characterization of muscle filamin isoforms suggests a possible role of $\gamma$-filamin/ABP-L in sarcomeric Z-disc formation. Cell Motil. Cytoskelet. 2000, 45, 149-162. [CrossRef]

27. Takada, F.; Vander Woude, D.L.; Tong, H.Q.; Thompson, T.G.; Watkins, S.C.; Kunkel, L.M.; Beggs, A.H. Myozenin: An $\alpha$-actinin- and $\gamma$-filamin-binding protein of skeletal muscle Z lines. Proc. Natl Acad Sci. USA 2001, 98, 1595-1600. [PubMed]

28. Xie, Z.; Xu, W.; Davie, E.W.; Chung, D.W. Molecular cloning of human ABPl, an actin-binding protein homologue. Biochem. Biophys. Res. Commun. 1998, 251, 914-919. [CrossRef] [PubMed]

29. Dalkilic, I.; Schienda, J.; Thompson, T.G.; Kunkel, L.M. Loss of filaminc (FLNC) results in severe defects in myogenesis and myotube structure. Mol. Cell. Biol. 2006, 26, 6522-6534. [CrossRef] [PubMed]

30. Bakay, M.; Wang, Z.; Melcon, G.; Schiltz, L.; Xuan, J.; Zhao, P.; Sartorelli, V.; Seo, J.; Pegoraro, E.; Angelini, C.; et al. Nuclear envelope dystrophies show a transcriptional fingerprint suggesting disruption of Rb-myoD pathways in muscle regeneration. Brain A J. Neurol. 2006, 129, 996-1013. [CrossRef] [PubMed]

31. Dadgar, S.; Wang, Z.; Johnston, H.; Kesari, A.; Nagaraju, K.; Chen, Y.W.; Hill, D.A.; Partridge, T.A.; Giri, M.; Freishtat, R.J.; et al. Asynchronous remodeling is a driver of failed regeneration in duchenne muscular dystrophy. J. Cell Biol. 2014, 207, 139-158. [CrossRef] [PubMed]

32. Greene, C.S.; Krishnan, A.; Wong, A.K.; Ricciotti, E.; Zelaya, R.A.; Himmelstein, D.S.; Zhang, R.; Hartmann, B.M.; Zaslavsky, E.; Sealfon, S.C.; et al. Understanding multicellular function and disease with human tissue-specific networks. Nat. Genet. 2015, 47, 569-576. [CrossRef] [PubMed]

33. Rockberg, J.; Uhlen, M. Prediction of antibody response using recombinant human protein fragments as antigen. Protein Sci. A Publ. Protein Soc. 2009, 18, 2346-2355. [CrossRef] [PubMed] 
34. Ponten, F.; Gry, M.; Fagerberg, L.; Lundberg, E.; Asplund, A.; Berglund, L.; Oksvold, P.; Bjorling, E.; Hober, S.; Kampf, C.; et al. A global view of protein expression in human cells, tissues, and organs. Mol. Syst. Biol. 2009, 5. [CrossRef] [PubMed]

35. Lindskog, C. The potential clinical impact of the tissue-based map of the human proteome. Expert Rev. Proteom. 2015, 12, 213-215. [CrossRef] [PubMed]

36. Binder, J.X.; Pletscher-Frankild, S.; Tsafou, K.; Stolte, C.; O’Donoghue, S.I.; Schneider, R.; Jensen, L.J. COMPARTMENTS: Unification and visualization of protein subcellular localization evidence. Database 2014. [CrossRef] [PubMed]

37. Hauser, M.A.; Horrigan, S.K.; Salmikangas, P.; Torian, U.M.; Viles, K.D.; Dancel, R.; Tim, R.W.; Taivainen, A.; Bartoloni, L.; Gilchrist, J.M.; et al. Myotilin is mutated in limb girdle muscular dystrophy 1A. Hum. Mol. Genet. 2000, 9, 2141-2147. [CrossRef] [PubMed]

38. Fischer, D.; Clemen, C.S.; Olive, M.; Ferrer, I.; Goudeau, B.; Roth, U.; Badorf, P.; Wattjes, M.P.; Lutterbey, G.; Kral, T.; et al. Different early pathogenesis in myotilinopathy compared to primary desminopathy. Neuromuscul. Disord. NMD 2006, 16, 361-367. [CrossRef] [PubMed]

39. Penisson-Besnier, I.; Talvinen, K.; Dumez, C.; Vihola, A.; Dubas, F.; Fardeau, M.; Hackman, P.; Carpen, O.; Udd, B. Myotilinopathy in a family with late onset myopathy. Neuromuscul. Disord. NMD 2006, 16, 427-431. [CrossRef] [PubMed]

40. Pegoraro, E.; Hoffman, E.P. Limb-Girdle Muscular Dystrophy Overview. In Genereviews(r); Pagon, R.A., Adam, M.P., Ardinger, H.H., Wallace, S.E., Amemiya, A., Bean, L.J.H., Bird, T.D., Fong, C.T., Mefford, H.C., Smith, R.J.H., et al, Eds.; GeneReviews: Seattle, WA, USA, 1993.

41. Polge, C.; Attaix, D.; Taillandier, D. Role of E2-Ub-conjugating enzymes during skeletal muscle atrophy. Front. Physiol. 2015, 6. [CrossRef] [PubMed]

42. Witt, S.H.; Granzier, H.; Witt, C.C.; Labeit, S. MURF-1 and MURF-2 target a specific subset of myofibrillar proteins redundantly: Towards understanding MURF-dependent muscle ubiquitination. J. Mol. Biol. 2005, 350, 713-722. [CrossRef] [PubMed]

43. Salmikangas, P.; van der Ven, P.F.; Lalowski, M.; Taivainen, A.; Zhao, F.; Suila, H.; Schroder, R.; Lappalainen, P.; Furst, D.O.; Carpen, O. Myotilin, the limb-girdle muscular dystrophy 1A (LGMD1A) protein, cross-links actin filaments and controls sarcomere assembly. Hum. Mol. Genet. 2003, 12, 189-203. [CrossRef] [PubMed]

44. Loo, D.T.; Kanner, S.B.; Aruffo, A. Filamin binds to the cytoplasmic domain of the $\beta 1$-integrin. Identification of amino acids responsible for this interaction. J. Biol. Chem. 1998, 273, 23304-23312. [CrossRef] [PubMed]

45. Faulkner, G.; Pallavicini, A.; Comelli, A.; Salamon, M.; Bortoletto, G.; Ievolella, C.; Trevisan, S.; Kojic, S.; Dalla Vecchia, F.; Laveder, P.; et al. FATZ, a filamin-, actinin-, and telethonin-binding protein of the Z-disc of skeletal muscle. J. Biol. Chem. 2000, 275, 41234-41242. [CrossRef] [PubMed]

46. Linnemann, A.; van der Ven, P.F.; Vakeel, P.; Albinus, B.; Simonis, D.; Bendas, G.; Schenk, J.A.; Micheel, B.; Kley, R.A.; Furst, D.O. The sarcomeric Z-disc component myopodin is a multiadapter protein that interacts with filamin and $\alpha$-actinin. Eur. J. Cell Biol. 2010, 89, 681-692. [CrossRef] [PubMed]

47. Kley, R.A.; Hellenbroich, Y.; van der Ven, P.F.; Furst, D.O.; Huebner, A.; Bruchertseifer, V.; Peters, S.A.; Heyer, C.M.; Kirschner, J.; Schroder, R.; et al. Clinical and morphological phenotype of the filamin myopathy: A Study of 31 German Patients. Brain A J. Neurol. 2007, 130, 3250-3264. [CrossRef] [PubMed]

48. Luan, X.; Hong, D.; Zhang, W.; Wang, Z.; Yuan, Y. A novel heterozygous deletion-insertion mutation (2695-2712 del/GTTTGT ins) in exon 18 of the filamin C gene causes filaminopathy in a large chinese family. Neuromuscul. Disord. NMD 2010, 20, 390-396. [CrossRef] [PubMed]

49. Shatunov, A.; Olive, M.; Odgerel, Z.; Stadelmann-Nessler, C.; Irlbacher, K.; van Landeghem, F.; Bayarsaikhan, M.; Lee, H.S.; Goudeau, B.; Chinnery, P.F.; et al. In-frame deletion in the seventh immunoglobulin-like repeat of filamin c in a family with myofibrillar myopathy. Eur. J. Hum. Genet. EJHG 2009, 17, 656-663. [CrossRef] [PubMed]

50. Vorgerd, M.; van der Ven, P.F.; Bruchertseifer, V.; Lowe, T.; Kley, R.A.; Schroder, R.; Lochmuller, H.; Himmel, M.; Koehler, K.; Furst, D.O.; et al. A mutation in the dimerization domain of filamin C causes a novel type of autosomal dominant myofibrillar myopathy. Am. J. Hum. Genet. 2005, 77, 297-304. [CrossRef] [PubMed] 
51. Neumann, M.; Sampathu, D.M.; Kwong, L.K.; Truax, A.C.; Micsenyi, M.C.; Chou, T.T.; Bruce, J.; Schuck, T.; Grossman, M.; Clark, C.M.; et al. Ubiquitinated TDP-43 in frontotemporal lobar degeneration and amyotrophic lateral sclerosis. Science 2006, 314, 130-133. [CrossRef] [PubMed]

52. Schmid, B.; Hruscha, A.; Hogl, S.; Banzhaf-Strathmann, J.; Strecker, K.; van der Zee, J.; Teucke, M.; Eimer, S.; Hegermann, J.; Kittelmann, M.; et al. Loss of als-associated TDP-43 in zebrafish causes muscle degeneration, vascular dysfunction, and reduced motor neuron axon outgrowth. Proc. Natl. Acad. Sci. USA 2013, 110, 4986-4991. [CrossRef] [PubMed]

(C) 2016 by the authors; licensee MDPI, Basel, Switzerland. This article is an open access article distributed under the terms and conditions of the Creative Commons by Attribution (CC-BY) license (http:/ / creativecommons.org/licenses/by/4.0/). 